\title{
1 Measuring radon-222 in soil gas with high spatial and temporal resolution
}

2

3 Darren Huxtable ${ }^{1}$

4

5 David Read ${ }^{2}$

6

7 George Shaw ${ }^{1}$

8

$9{ }^{1}$ University of Nottingham, School of Biosciences, Sutton Bonington Campus, Leicestershire, LE12 10 5RD, UK

11

$12{ }^{2}$ Loughborough University, Department of Chemistry, Ashby Road, Loughborough, Leicestershire, 13 LE11 3TU, UK. Current address Department of Chemistry, University of Surrey, Guildford, GU2 7XH, 14 UK 
18 In order to exploit ${ }^{222} \mathrm{Rn}$ as a naturally-occurring tracer in soils we need to sample and measure radon isotopes in soil gas with high spatial and temporal resolution, without disturbing in situ activity concentrations and fluxes. Minimization of sample volume is key to improving the resolution with which soil gas can be sampled; an analytical method is then needed which can measure radon with appropriate detection limits and precision for soil gas tracer studies. We have designed a soil gas probe with minimal internal dead volume to allow us to sample soil gas volumes of $45 \mathrm{~cm}^{3}$. Radon222 is extracted from these samples into a mineral oil-based scintillation cocktail before counting on a conventional liquid scintillation counter. A detection limit of $320 \mathrm{~Bq} \mathrm{~m}^{-3}$ (in soil gas) is achievable with a one hour count. This could be further reduced but, in practice, is sufficient for our purpose since ${ }^{222} \mathrm{Rn}$ in soil gas typically ranges from $2,000-50,000 \mathrm{~Bq} \mathrm{~m}^{-3}$. The method is simple and provides several advantages over commonly used field-portable instruments, including smaller sample volumes, speed of deployment and reliability under field conditions. The major limitation is the need to count samples in a liquid scintillation counter within $2-3$ days of collection, due to the short (3.824 day) radioactive half-life of ${ }^{222} \mathrm{Rn}$. The method is not applicable to the very short-lived 32 (55 second half-life) ${ }^{220} \mathrm{Rn}$.

33

\section{KEY WORDS} radon-222; ${ }^{222} \mathrm{Rn}$; soil gas; tube sampler; liquid scintillation counting; ionisation chamber 
Radon isotopes $\left({ }^{220} \mathrm{Rn}\right.$ and $\left.{ }^{222} \mathrm{Rn}\right)$ occur naturally in all soils due to the decay of the parent nuclides ${ }^{224} \mathrm{Ra}$ and ${ }^{226} \mathrm{Ra}$, which ultimately derive from radioactive decay of ${ }^{232} \mathrm{Th}$ and ${ }^{238} \mathrm{U}$, respectively. Radon-220 (thoron) and ${ }^{222} \mathrm{Rn}$ (radon) both undergo alpha decay; each gives rise to a series of shortlived alpha- and beta-emitting progeny which can impart significant radiation doses when inhaled. Thus, many studies of radon gas are driven by the need to quantify radiation doses due to the efflux of radon from soil into the atmosphere above, especially when this occurs into buildings. However, radon gas can also be used as a naturally-occurring tracer which can assist in predicting earthquake risk (Papastefanou, 2007) and in quantifying gas transport in soils. Radon flux measurements have previously been used to determine diffusive properties of surface soils (Dorr and Munnich, 1990; Lehman et al., 2000; Huxol et al., 2013) and also the diffusive transport characteristics of the near surface atmosphere within short vegetation canopies (Nemitz et al., 2009). There is potential to use radon in a wider range of applications, but we need flexible and easily applied methods to measure activity concentrations in soil profiles. Soils are complex: porosity and tortuosity vary spatially, whereas water content varies both spatially and temporally. Each of these properties exerts a strong influence on the effective diffusivity of gases, including radon, in soils (Rogers and Nielson, 1991). Thus, we need to be able to sample and measure radon isotopes in soil gas with high spatial and temporal resolution, preferably in ways that disturb in situ activity concentrations and fluxes as little as possible.

Numerous methods can be used to sample and measure radon in soil gas. These include detectors such as the Clipperton probe (Monnin and Seidel, 1998), Barasol ${ }^{\mathrm{TM}}$ (www.algade.com) or electret ion chambers which can be embedded directly in the soil for periods ranging from days to years (Antonopoulos-Domis et al., 2009). For long term measurements, gas-permeable tubes can be buried in the soil, through which air is circulated and radon measured at the surface using a suitable detector (Lehmann et al., 2000). Shorter-term measurements can be made by driving narrow tube samplers into the soil and extracting soil gas under suction at defined depths. Dorr and Munnich (1990) sampled soil gas by driving a narrow $(6 \mathrm{~mm} \varnothing)$ stainless steel tube with a perforated tip into the soil to depths ranging from $5 \mathrm{~cm}$ to as deep as $10 \mathrm{~m}$. They extracted $200-300 \mathrm{~cm}^{3}$ of soil gas by pumping through the tip of the sampler at a rate of $400 \mathrm{~cm}^{3}$ minute ${ }^{-1}$. In a soil with air-filled porosity of $40 \%$, a soil gas sample of $300 \mathrm{~cm}^{3}$ will be drawn from a sphere with $5.64 \mathrm{~cm}$ radius, assuming homogeneous and isotropic pore structure. This would give an uncertainty of almost $12 \mathrm{~cm}$ on the vertical position of the sample. As soil wetness increases, so does this uncertainty; with an air-filled 
porosity of $20 \%$, the notional sampling sphere of a $300 \mathrm{~cm}^{3}$ gas sample has a radius greater than 7 $\mathrm{cm}$ and the minimum spacing of adjacent samples is, for all practical purposes, $10 \mathrm{~cm}$. Similarly, the minimum depth of sampling is $10 \mathrm{~cm}$ below the soil surface. Reducing the volume of the soil gas sample will increase the spatial precision with which it can be taken (Born et al., 1990). Figure 1 indicates that, as sample volume is reduced to less than $100 \mathrm{~cm}^{3}$, the effective sampling radius, hence the positional uncertainty on the sample, falls rapidly. Figure 1 also shows that the smaller the gas sample, the less the influence of soil wetness (i.e. effective porosity) on the positional uncertainty on the sample. Taking smaller soil gas samples also reduces the risk of drawing air from the above-soil atmosphere between the outer surface of the sampling tube and the soil.

Some field-portable radon monitoring instruments (e.g. RAD7 ${ }^{\mathrm{TM}}$ and AlphaGUARD'm) are able to pump soil gas from sampling tubes, either in one-off volumes or on a continuous cycle in which samples are taken every few minutes for as long as necessary (www.durridge.com; www.saphymo.com). The minimum volumes required for one-off samples are in the order of $2 \mathrm{dm}^{3}$, with corresponding sampling radii ranging from $10-20 \mathrm{~cm}$, depending on the effective porosity of the soil; some studies using stand-alone radon monitors have used sample volumes as large as $5 \mathrm{dm}^{3}$ (Schroth et al., 2012). While such instruments are convenient to use, they are limited in their ability to take samples with high spatial and temporal resolution.

The aim of the current study was to develop and test an alternative method to allow small volume samples of soil gas to be collected with high precision, both spatially and temporally, and for these samples to be analysed for ${ }^{222} \mathrm{Rn}$ with sufficient accuracy and precision for soil gas transport studies.

\section{METHODS}

A probe (Figure 2) was designed to allow small volume samples of soil gas to be taken quickly and conveniently down to soil depths of 1 metre. This consists of a length of aluminium tube $(8 \mathrm{~mm}$ external diameter) with a pointed tip behind which numerous $1 \mathrm{~mm}$ holes are drilled over a length of $2 \mathrm{~cm}$. A flexible silicone rubber tube with narrow $(0.8 \mathrm{~mm})$ internal bore passes through the external aluminium tube and is sealed into position near the perforated sampling tip with a silicone rubber plug. The design minimises 'dead volume' within the sampler $\left(\sim 0.5 \mathrm{~cm}^{3}\right.$ in the sampler head and $0.5 \mathrm{~cm}^{3} \mathrm{~m}^{-1}$ in the silicone tube). The length of aluminium tube can be varied from $15 \mathrm{~cm}$ to 1 metre, to suit the required depth of sampling. A brass elbow joint at the upper end of the aluminium tube provides a conduit in which the silicone rubber tube is protected from the pressure 
needed to push the tube sampler into the soil to the required sampling depth. A plastic tap with a Luer fitting allows a disposable $20 \mathrm{~cm}^{3}$ syringe to be attached to the end of the silicone rubber tube this syringe is used to withdraw a gas sample through the sampling probe from the required soil depth.

In practice the first aliquot $\left(<5 \mathrm{~cm}^{3}\right)$ of soil gas withdrawn from the sampler, which includes the 'dead volume', is discarded. $15 \mathrm{~cm}^{3}$ of soil gas are then withdrawn and injected into a pre-evacuated glass vial (Exetainer ${ }^{\circledR}$, www.exetainer.com) through a rubber septum. Each vial $\left(12 \mathrm{~cm}^{3}\right)$ is prepared by half-filling with $6.6 \mathrm{~cm}^{3}$ of a liquid scintillation cocktail (Pro-Scint $\mathrm{Rn}^{\mathrm{TM}}$, Meridian Biotechnologies Ltd.), leaving an evacuated volume of $5.4 \mathrm{~cm}^{3}$. Injecting $15 \mathrm{~cm}^{3}$ of soil gas into this volume results in an 'overpressure' of approximately 2 bar. A further two $15 \mathrm{~cm}^{3}$ aliquots of soil gas are withdrawn from the soil via the sampling probe and injected into separate Exetainer ${ }^{\circledR}$ vials, thus giving triplicate vials for each sampling point and a nominal total of $45 \mathrm{~cm}^{3}$ of soil gas extracted per sampling point (experimental analysis of Type A error gave an actual value of $44.89 \pm 0.03 \mathrm{~cm}^{3}$ ). If a vertical profile of soil gas samples is needed, the probe is inserted to the shallowest depth (usually $10 \mathrm{~cm}$ from the soil surface) from which triplicate gas samples are withdrawn. The probe is then pushed to the next sampling depth and the procedure repeated until soil gas samples have been taken over the required sequence of depth intervals.

Once injected into the Exetainer ${ }^{\circledast}$ vials, ${ }^{220} \mathrm{Rn}$ and ${ }^{222} \mathrm{Rn}$ are free to partition into the liquid scintillation cocktail. Pro-Scint $\mathrm{Rn}^{\mathrm{TM}}$ is mineral oil-based and contains $20-40 \%$ 'pseudocumene' (1,2,4-trimethylbenzene) as a liquid scintillator. It was chosen for this application as it is specifically formulated to 'extract' radon from water or gas samples with a partition coefficient of approximately 50 (Clever, 1979). The extraction process is facilitated by shaking the vials vigorously by hand before transporting to the laboratory where, after at least 1 hour contact time, the liquid contents of the triplicate Exetainer ${ }^{\circledR}$ vials are decanted into a single low-potassium borosilicate glass scintillation vial, giving a $20 \mathrm{~cm}^{3}$ volume of scintillation cocktail per vial. The scintillation vials are then placed into a liquid scintillation counter (we used a Packard Tri-Carb 2100TR) where they are dark-adjusted for three hours before counting across an energy range from 0 to $2 \mathrm{MeV}$. By the time the vials are counted any ${ }^{220} \mathrm{Rn}(\mathrm{T} 1 / 2 \sim 55 \mathrm{~s})$ has completely decayed and counts collected should result solely from ${ }^{222} \mathrm{Rn}$ and its short-lived progeny, ${ }^{218} \mathrm{Po},{ }^{214} \mathrm{~Pb},{ }^{214} \mathrm{Bi}$ and ${ }^{214} \mathrm{Po}$. With physical halflives of 3.11 minutes, 26.8 minutes, 19.9 minutes and 0.00016 seconds, respectively, these decay products need approximately four hours to achieve secular equilibrium with ${ }^{222} \mathrm{Rn}$. Thus, the darkadjustment period, plus the time needed to count a reagent blank 'background' sample (1 hour), 
ensure that the samples contain combined activities of parent and progeny which are representative of the original ${ }^{222} \mathrm{Rn}$ activity in each soil gas sample.

Each sample is counted for one hour and the sample activities reported in counts per minute after subtraction of background counts (CPM net). A reliable calibration is then needed to convert CPM net values to volumetric activity concentrations $\left(\mathrm{Bq} \mathrm{m}{ }^{-3}\right)$. A small quantity of ${ }^{226} \mathrm{Ra}$-containing scale (barium-radium sulphate, derived from deposits within an industrial pipe) was placed in a sealed chamber within the laboratory and ${ }^{222} \mathrm{Rn}$ emanating from the physical decay of ${ }^{226} \mathrm{Ra}$ was sampled using the continuous flow mode of a pulse-counting ionisation chamber (AlphaGUARD'M PQ2000 PRO radon monitor; www.saphymo.com) with a stated measurement range from $2-2 \times 10^{6} \mathrm{~Bq} \mathrm{~m}^{-3}$ for ${ }^{222} \mathrm{Rn}$. The AlphaGUARD ${ }^{\mathrm{TM}}$ is factory calibrated using a NIST standard (SAPHYMO, pers. comm.) and thus provides an accurate baseline of measured ${ }^{222} \mathrm{Rn}$ activity concentrations against which to compare independent measurements using liquid scintillation counting (LSC). During measurement of a wide range of ${ }^{222} \mathrm{Rn}$ activity concentrations $\left(280-1.3 \times 10^{5} \mathrm{~Bq} \mathrm{~m}^{-3}\right)$ in the laboratory chamber system, triplicate $15 \mathrm{~cm}^{3}$ syringe samples of gas were taken directly from the ionisation chamber of the AlphaGUARD ${ }^{\mathrm{TM}}$ monitor and treated as previously described for soil gas samples. These samples were analysed using LSC and compared with data obtained using the AlphaGUARD ${ }^{\mathrm{TM}}$. The AlphaGUARD ${ }^{\text {TM }}$ manufacturer's stated calibration error is $3 \%$, not including the uncertainty on the primary standard which is not provided. We could not, therefore, quantify the complete Type B uncertainty contributed by the primary calibration of the AlphaGUARD ${ }^{\mathrm{Tm}}$, though the 1-sigma (Type A) counting uncertainties of both the AlphaGUARD ${ }^{\mathrm{TM}}$ and LSC methods were tightly constrained, as shown in Figure 5.

To verify the comparability of ${ }^{222} \mathrm{Rn}$ measurements using both methods in the field, a series of soil gas samples were taken from an experimental plot at Sutton Bonington, UK $\left(52.833^{\circ} \mathrm{N}, 1.249^{\circ} \mathrm{W}\right)$. Samples were taken at $60 \mathrm{~cm}$ depth from randomised points within a $15 \times 15 \mathrm{~m}$ area on seven different days between September and December 2013. Soil gas samples were taken using the sampling probes described above. The soil gas was extracted using an AlphaGUARD ${ }^{\text {TM }}$ radon monitor coupled to an AlphaPUMP'm, at a rate of $1 \mathrm{dm}^{3}$ minute ${ }^{-1}$ for 2 minutes. The volume of the ionisation chamber is $0.62 \mathrm{dm}^{3}$, hence approximately two chamber volumes were pumped through to purge the monitor and the third chamber volume was sealed in the ionisation chamber for counting. A time interval of 1 minute was used to integrate the counts collected and an overall counting period of 30 minutes was used for each soil gas sample. As in the laboratory chamber experiment, triplicate $15 \mathrm{~cm}^{3}$ syringe samples of gas were taken directly from the ionisation chamber of the AlphaGUARD ${ }^{\mathrm{TM}}$ 
172 monitor and treated as previously described for soil gas samples. These samples were analysed using LSC and compared with data obtained using the AlphaGUARD ${ }^{\mathrm{TM}}$ in the field.

The same experimental plot was used to sample soil gas over depth profiles from 10 to $60 \mathrm{~cm}$. These samples were taken at randomly located points within the $15 \times 15 \mathrm{~m}$ experimental area by inserting the sampling probe in $10 \mathrm{~cm}$ increments, as described above. The overall time taken to insert the probe to the required depth and then to extract $3 \times 15 \mathrm{~cm}^{3}$ aliquots of soil gas was approximately 5 minutes, giving a combined sampling time of 25 - 30 minutes per profile. Gas samples were injected into Exetainer ${ }^{\circledast}$ vials, prepared as described above, and taken directly to the laboratory for analysis. A further field test of the method was made by carrying out a survey of the horizontal distribution of ${ }^{222} \mathrm{Rn}$ activity concentrations in soil developed in alluvium above the junction between two rock types in the Peak District, Central England. Soil gas was sampled on Cromford Meadow $\left(53.11^{\circ} \mathrm{N}, 1.55^{\circ} \mathrm{W}\right.$ ) at $15 \mathrm{~cm}$ depth along a transect perpendicular to the boundary between the uraniferous Bowland Shale and Lower Carboniferous Limestone. The approximate location of the boundary was determined using a geological map (BGS, 1963) and magnetic bearing from a visible fault line. Samples were then collected over a distance of $11 \mathrm{~m}$ at $1 \mathrm{~m}$ spacings. This sampling exercise took less than one hour.

\section{RESULTS and DISCUSSION}

191

Minimization of sample volume is key to improving the spatial and temporal resolution with which soil gas can be sampled although few studies on soil gas sampling specifically address this problem. In a radon detector such as AlphaGUARD ${ }^{\mathrm{T}}$, the volume of the ionization chamber dictates the minimum soil gas volume which can be measured. When using LSC to measure radon in soil gas there is a balance between the volume of gas sampled and the count rate detected. During development of our method we took gas sample volumes ranging from $10 \mathrm{~cm}^{3}-20 \mathrm{~cm}^{3}$, each taken in triplicate to give total sample volumes of $30 \mathrm{~cm}^{3}-60 \mathrm{~cm}^{3}$. The optimum volume was $45 \mathrm{~cm}^{3}$ (i.e. 3 $\times 15 \mathrm{~cm}^{3}$ ) which increased the count rate obtained from $30 \mathrm{~cm}^{3}$ samples in a linear fashion (Figure 3). Larger $\left(60 \mathrm{~cm}^{3}\right)$ samples further increased the count rate, but the gain in counts was not proportional to the increased gas volume taken.

Liquid scintillation counting of soil gas samples measures the combined contribution from alpha and beta particles from ${ }^{222} \mathrm{Rn}$ and its short-lived progeny. It is not possible from the energy spectrum 
identify the presence of ${ }^{222} \mathrm{Rn}$. However, due to the fact that its 3.824 day radioactive half-life is considerably longer than the half-lives of its four immediate descendants, it is possible to identify ${ }^{222} \mathrm{Rn}$ as the main source of radioactivity in a sample by comparing the declining count rate over several days with the theoretical physical decay curve for ${ }^{222} \mathrm{Rn}$. Ingrowth of the much longer-lived ${ }^{210} \mathrm{~Pb}(\mathrm{~T} 1 / 2=22.3$ years$)$ is too slow to contribute to the count rate over a period of hours to days. Figure 4 compares repeated counts of the same soil gas sample with the theoretical decay curve for ${ }^{222} \mathrm{Rn}$, indicating that the counts were indeed due solely to ${ }^{222} \mathrm{Rn}$ and its short-lived progeny. Figure 4 also indicates that count rates in a typical soil gas sample were achieved with 2-sigma precision ranging from $2-10 \%$.

Having established that ${ }^{222} \mathrm{Rn}$ could be identified and counted with good precision in a composite soil gas sample of $45 \mathrm{~cm}^{3}$, a calibration curve between the AlphaGUARD ${ }^{\mathrm{TM}}$ (Bq m $\mathrm{m}^{-3}$ ) and LSC (CPM net) methods was drawn, based on measurements in a laboratory chamber using barium-radium sulphate as a source of ${ }^{222} \mathrm{Rn}$. This curve was approximately linear but could be described most accurately, especially at LSC count rates less than approximately 50 CPM, using a power function with an exponent just greater than 1 (1.0435). This weakly non-linear function (the AlphaGUARD ${ }^{\mathrm{TM}}$ manufacturer's stated linearity error is $<3 \%)$ provided a strong fit $\left(R^{2}=0.996\right)$ to the experimental measurements over a range of ${ }^{222} \mathrm{Rn}$ activity concentrations spanning almost four orders of magnitude. The limit of detection was calculated (according to Currie, 1968) to be 3.33 CPM net for a 60 minute count time; this equates to a ${ }^{222} \mathrm{Rn}$ activity concentration of $320 \mathrm{~Bq} \mathrm{~m}^{-3}$. Doubling the count time to 120 minutes would reduce the limit of detection to 2.35 CPM net, equivalent to 220 $\mathrm{Bq} \mathrm{m}^{-3}$. The limit of detection may be further decreased by raising the lower energy threshold above zero $\mathrm{MeV}$ which would exclude the high background lower energy radiation, thus raising the signalto-noise ratio (Genereux and Hemond, 1991). Our current detection limit is comparable to LSC methods using other liquid scintillation counters, including Quantulus ${ }^{\mathrm{TM}}$ (Buzinny et al., 2009). It is relatively high compared with some other methods, including instrumental detectors such as RAD7 $7^{\mathrm{TM}}$ and AlphaGUARD ${ }^{\mathrm{Tm}}$ (typically $20 \mathrm{~Bq} \mathrm{~m}^{-3}$ ), but suitable for most soil gas applications; activity concentrations of ${ }^{222} \mathrm{Rn}$ measured in soil gas commonly range from 2,000 -50,000 Bq m${ }^{-3}$ (Schubert et al., 2002).

In our field comparison of AlphaGUARD ${ }^{\mathrm{TM}}$ and LSC, ${ }^{222} \mathrm{Rn}$ activity concentrations in soil gas ranged from $936( \pm 780)-24,004( \pm 3448) \mathrm{Bq} \mathrm{m}^{-3}$ (1-sigma uncertainties from AlphaGUARD ${ }^{\text {TM }}$ measurements in parentheses). Figure 6 shows data from a typical AlphaGUARD ${ }^{\text {TM }}$ counting cycle which lasted 30 minutes, during which counts were integrated over one minute intervals. An initial peak in activity 
concentration at $2-3$ minutes is given by the combined counts from ${ }^{220} \mathrm{Rn}$ and ${ }^{222} \mathrm{Rn}$. After 5 minutes, the counts from ${ }^{220} \mathrm{Rn}$ have been lost by radioactive decay and counts from ${ }^{222} \mathrm{Rn}$ and its short-lived progeny are collected for the next 20 minutes before purging the ionization chamber for 5 minutes so that the next sample can be collected. The average ${ }^{222} \mathrm{Rn}$ activity concentration for the sample is calculated from the 1 minute counts taken between 5 and 25 minutes. $45 \mathrm{~cm}^{3}$ gas samples were taken directly from the ionization chamber to be analysed by LSC and the results of the two methods are compared in Figure 7. The relationship between AlphaGUARD ${ }^{\mathrm{TM}}$ activity concentrations and CPM net by LSC was more strongly log-linear than in the laboratory chamber experiment and could be described using a power function with an exponent of $1.253\left(R^{2}=0.859\right)$. The predictive accuracy of the calibration curve in Figure 5 was tested by converting CPM net values from the field samples in Figure 7 to ${ }^{222} \mathrm{Rn}$ activity concentrations $\left(\mathrm{Bq} \mathrm{m}^{-3}\right)$. These calculated activity concentrations were then compared with those measured directly using AlphaGUARD ${ }^{\mathrm{TM}}$ in the field (Figure 8). Linear regression of the two data sets yielded a coefficient of determination $\left(R^{2}\right)$ of 0.742 . A $\chi^{2}$ test $(p=0)$ allows us to conclude that the laboratory calibration between the two methods is sufficiently reliable for LSC to be used as a stand-alone method for ${ }^{222} \mathrm{Rn}$ detection in small soil gas samples.

Given the design of the soil gas sampling probe, the method is particularly suitable for measuring $\mathrm{cm}$ ) to $1 \mathrm{~m}$. Two example profiles are shown in Figure 9, both measured at randomly-located points within the $15 \times 15 \mathrm{~m}$ experimental plot described above. Several published studies show that ${ }^{222} \mathrm{Rn}$ diffusion in soils can be described by a single effective diffusion coefficient (Nazaroff, 1992). This is convenient since it allows ${ }^{222} \mathrm{Rn}$ fluxes at the soil surface to be calculated by fitting an analytical solution of the 1-D diffusion equation. However, it is known that complexities arise in the distribution of radon through the soil profile due to changes in the effective porosity of the soil and the radon emanation rate associated with variations in soil mineralogy and other properties. For example, Antonopoulos-Domis et al. (2009) showed that the radon activity concentration profile in a Greek soil was strongly influenced by a change from sandy to clayey texture. In our study, the shape of the ${ }^{222} \mathrm{Rn}$ activity concentration profiles was not monotonic, but clearly influenced by changes in soil porosity. In Figure 9 this can be seen at a depth of $30-40 \mathrm{~cm}$ where the soil texture changed from sandy loam in the upper part of the profile to sandy clay below. A simple analytical solution of the 1-D diffusion equation cannot be fitted to either of the two ${ }^{222} \mathrm{Rn}$ profiles in Figure 9 since the effective diffusion coefficient is not constant with depth. It is possible, however, to approximate the shapes of the measured ${ }^{222} \mathrm{Rn}$ activity concentration profiles with a numerical solution of the 1-D diffusion equation, assuming a vertically uniform ${ }^{222} \mathrm{Rn}$ production rate (calculated according to 
274 Chamberlain, 1991) and discrete diffusion coefficients for different parts of the soil profile. In Figure 2759 (a) the ${ }^{222} \mathrm{Rn}$ production rate was assumed to be $0.056 \mathrm{~Bq} \mathrm{~m}^{-3} \mathrm{~s}^{-1}$ and the effective diffusion coefficients were $5.25 \times 10^{-6} \mathrm{~m}^{2} \mathrm{~s}^{-1}$ for the $0-10 \mathrm{~cm}$ soil depth, $1.75 \times 10^{-6} \mathrm{~m}^{2} \mathrm{~s}^{-1}$ for the $10-30 \mathrm{~cm}$ soil depth and $1.05 \times 10^{-7} \mathrm{~m}^{2} \mathrm{~s}^{-1}$ for the $30-70 \mathrm{~cm}$ soil depth. For Figure $9(\mathrm{~b})$ the assumed ${ }^{222} \mathrm{Rn}$ production rate was $0.1 \mathrm{~Bq} \mathrm{~m}^{-3} \mathrm{~s}^{-1}$ and the effective diffusion coefficients were $3.5 \times 10^{-6} \mathrm{~m}^{2} \mathrm{~s}^{-1}$ for the $0-40 \mathrm{~cm}$ soil depth and $1.05 \times 10^{-7} \mathrm{~m}^{2} \mathrm{~s}^{-1}$ for the $40-70 \mathrm{~cm}$ soil depth. The diffusion coefficients for both profiles lie within the range of effective diffusion coefficients for ${ }^{222} \mathrm{Rn}$ in soils presented by Nazaroff (1992). One of the most useful applications of measured soil activity concentration profiles of ${ }^{222} \mathrm{Rn}$ is to estimate effective gas diffusion coefficients for soils, which can then be scaled to other important soil gases such as $\mathrm{CH}_{4}, \mathrm{CO}_{2}$ and $\mathrm{N}_{2} \mathrm{O}$ whose diffusive behaviour is difficult to estimate directly due to complications including interactions with soil organisms (eg. Born et al., 1990; Dorr and Munnich, 1990). The fact that different values of effective diffusion coefficients have to be used to model ${ }^{222} \mathrm{Rn}$ activity concentration profiles, especially in the upper soil layers, underlines the complexity of behaviour of radon gas in soils and the need for high spatial resolution measurements to provide better understanding of the factors which control its distribution and flux.

The second field test of our method involved a horizontal survey of ${ }^{222} \mathrm{Rn}$ in soil gas in the vicinity of a geological discontinuity which is suspected to result in a localised increase in radon flux at the soil surface due to authigenic uranium within the Bowland Shale (Leeder et al., 1990). The influence of underlying geology on radon activity concentrations in surface soil (10 $-30 \mathrm{~cm}$ depth) soil is expected to reduce with increasing thickness of soil overlying the bedrock. Nevertheless, Figure 10 shows that, within 2 metres of where the boundary was suspected to lie between the Bowland Shale and Carboniferous Limestone, ${ }^{222} \mathrm{Rn}$ activity concentrations in soil gas at $15 \mathrm{~cm}$ depth increased from a baseline of $10,000-15,000 \mathrm{~Bq} \mathrm{~m}^{-3}$ to a peak of $40,000 \mathrm{~Bq} \mathrm{~m}^{-3}$. The method of soil gas sampling and analysis described in this paper allowed us to identify a band of elevated radon concentration only 3 metres wide based on a field survey which took less than one hour.

The accuracy of the LSC method has been demonstrated by calibration against field and laboratory measurements using an instrumental radon detector (ALPHAGUARD ${ }^{\mathrm{TM}}$ ). The LSC method provided much better spatial resolution than the ALPHAGUARD ${ }^{\text {TM }}$ owing to the smaller gas volumes sampled. Another advantage of the LSC method is that, as long as a soil gas sample can be extracted, it is unaffected by soil moisture, unlike instruments such as the RAD7 ${ }^{\text {TM }}$. Szabo et al. (2013) have shown that seasonal variation in soil water content has a major influence on radon activity concentrations 
in soil gas. Our own field studies have shown that, if water content is too high (often the case in winter) then the physical process of extracting a soil gas sample is inhibited, although the analysis by LSC of any gas sample obtained is not compromised. Hence, the LSC method provides a promising way to explore variations in ${ }^{222} \mathrm{Rn}$ in relation to variable soil moisture contents from very dry to almost fully saturated. A disadvantage of LSC compared with instrumental methods is that it suffers from higher detection limits and so would not be generally suitable for measurements of radon in the free atmosphere unless used in conjunction with a pre-concentration method (Passo and Floekher, 1991; Buzinny, 1996); however, this is not required for most soil gas applications.

Another drawback to our method is that it is time-limited by the half-life of ${ }^{222} \mathrm{Rn}$. For the field studies we have carried out so far, it has been possible to return gas samples to the laboratory within 24 hours of collection; in practice, a 2 - 3 day delay between sample collection and analysis would be feasible. However, samples collected in remote locations may be too far from a LSC facility to allow this method to be used. One other shortcoming of the method is that it cannot be used to measure ${ }^{220} \mathrm{Rn}$, simply because its 55.6 second half-life is too short. For applications in which dual counting of radon and thoron are needed (e.g. Huxol et al., 2013) instrumental methods such as AlphaGUARD' ${ }^{\mathrm{TM}}$ and RAD7 ${ }^{\mathrm{TM}}$ would be needed.

\section{CONCLUSIONS}

327

We present a method for the sampling and analysis of soil gas for ${ }^{222} \mathrm{Rn}$ activity concentrations. Our primary motivation in proposing this method is to use measured ${ }^{222} \mathrm{Rn}$ activity concentration profiles in soils to improve quantitative understanding of the diffusion of radon and other important gases in soils whilst minimising any disturbance to soil gases in situ. To achieve this, our sampler is designed to minimise the volume of soil gas sampled and our preferred analytical method for the gas samples obtained is liquid scintillation counting (LSC). Analysis of soil gas samples by LSC has been rigorously compared with a commercially-available, factory calibrated ionisation chamber (AlphaGUARD ${ }^{\mathrm{TM}}$ ) and found to provide a convenient and appropriate method for the stated purpose.

339 DH was funded by a PhD studentship from the Midlands Energy Consortium, UK. We thank Dr David 340 Large (Faculty of Engineering, University of Nottingham) for his kind assistance with field work at 341 Cromford. 
1. Antonopoulos-Domis, M., S. Xanthos, A. Clouvas and D. Alifrangis (2009) Experimental and theoretical study of radon distribution in soil. Health Physics, 97(4), 322-331.

2. BGS (1963) Sheet 112 (Chesterfield), 1:50,000 Geology Series. British Geological Survey, Keyworth, Nottinghamshire, UK.

3. Born, M., H. Dorr and I. Levin (1990) Methane consumption in aerated soils of the temperate zone. Tellus, 42B, 2 - 8.

352

4. Buzinny, M. (1996) A new approach to determining ${ }^{222} \mathrm{Rn}$ in air using liquid scintillation counting. International Conference on Advances in Liquid Scintillation Spectrometry, edited by G. T. Coop D. D. Harkness, A. B. MacKenzie, B. F. Miller and E. M. Scott. RADIOCARBON 1996, pp. $137-140$.

5. Buzinny, M., V. Sakhno and M. Romanchenko (2009) LSC-based approach for radon in soil gas measurements. Advances in Liquid Scintillation Spectrometry, edited by J. Eikenberg, M Jäggi, H. Beer and H. Baehrle, LSC 2008, pp. 7 - 11.

6. Chamberlain, A. C. (1991) Radon. Chapter 1, pp. 1-60, in Radioactive Aerosols, Cambridge University Press.

7. Clever, H. L. ed. (1979) Krypton, Xenon and Radon, Solubility Data Series 2, Vol. 18, Pergamon Press, Oxford, UK.

8. Currie, L. A. (1968) Limits for qualitative detection and quantitative determination application to radiochemistry. Analytical Chemistry, 40, 586 - 593.

9. Dorr, H. and K. O. Munnich (1990) ${ }^{222} \mathrm{Rn}$ flux and soil air concentration profiles in WestGermany. Soil ${ }^{222} \mathrm{Rn}$ as tracer for gas transport in the unsaturated soil zone. Tellus $\mathrm{B}, 42 \mathrm{~B}$, $20-28$.

10. Genereux, D. P. and H. F. Hemond (1991) Measurement of the radon-222 content of soil gas by liquid scintillation counting. Chemical Geology (Isotope Geoscience Section), 87, 265-275. 
11. Huxol, S., M. Brennwald, R. Henneberger and R. Kipfer $(2013){ }^{220} \mathrm{Rn} /{ }^{222} \mathrm{Rn}$ isotope pair as a natural proxy for soil gas transport. Environmental Science \& Technology, 47 (24), 1404414050.

12. Leeder, M, R. Raiswell, H. Al-Biatty, A. McMahon and M. Hardman (1990) Carboniferous 383 stratigraphy, sedimentation and correlation of well 48/3-3 in the southern North Sea Basin; integrated use of palynology, natural gamma/sonic logs and carbon/sulphur geochemistry. Journal of the Geological Society, London, 147, 287 - 300.

13. Lehmann, B. E., Lehmann, M., Neftel, A., and Tarakanov, S. V. (2000) Radon-222 monitoring 388 of soil diffusivity. Geophysics Research Letters, 27(23), 3917-3920.

14. Monnin, M. and J. L. Seidel (1998) An automatic radon probe for earth science studies. Journal of Applied Geophysics, 39, 209 - 220.

392

15. Nazaroff, W. (1992) Radon transport from soil to air. Reviews of Geophysics, 30(2), 137 160.

16. Nemitz, E., B. Loubet, B. E. Lehmann, P. Cellier, A. Neftel, S. K. Jones, A. Hensen, B. Ihly, S. V. Tarakanov and M. A. Sutton (2009) Turbulence characteristics in grassland canopies and 399

17. Papastefanou, C. (2007) Measuring radon in soil gas and groundwaters: a review. Annals of 401 Geophysics, 50, 569-574.

402

403

404

405 implications for tracer transport. Biogeosciences Discussions, 6, 437-489.

18. Passo, C. J. and J. M. Floekher (1991) The LSC approach to radon counting in air and water. In: Scintillation Counting and Organic Scintillators, eds. H. Ross, J. E. Noakes and J. D. Spaulding, 32, 375-384.

19. Rogers, V. C. and K. K. Nielson (1991) Multiphase radon generation and transport in porous materials. Health Physics, 60, $807-815$. 

Above- and below-ground methane fluxes and methanotrophic activity in a landfill-cover soil. Waste Management, 32, 879 - 889.

413

21. Schubert, M., Freyer, K., Treutler, H. and Weiss, H. (2002). Using radon-222 in soil gas as an 415 indicator of subsurface contamination by non-aqueous phase liquids (NAPL). Geofisica Int., 41, 433-437.

22. Szabó, K. Z. , G. Jordan, Á. Horváth, C. Szabó (2013) Dynamics of soil gas radon 419 concentration in a highly permeable soil based on a long-term high temporal resolution observation series. Journal of Environmental Radioactivity, 124, 74-83. 
422

423

424

425

426

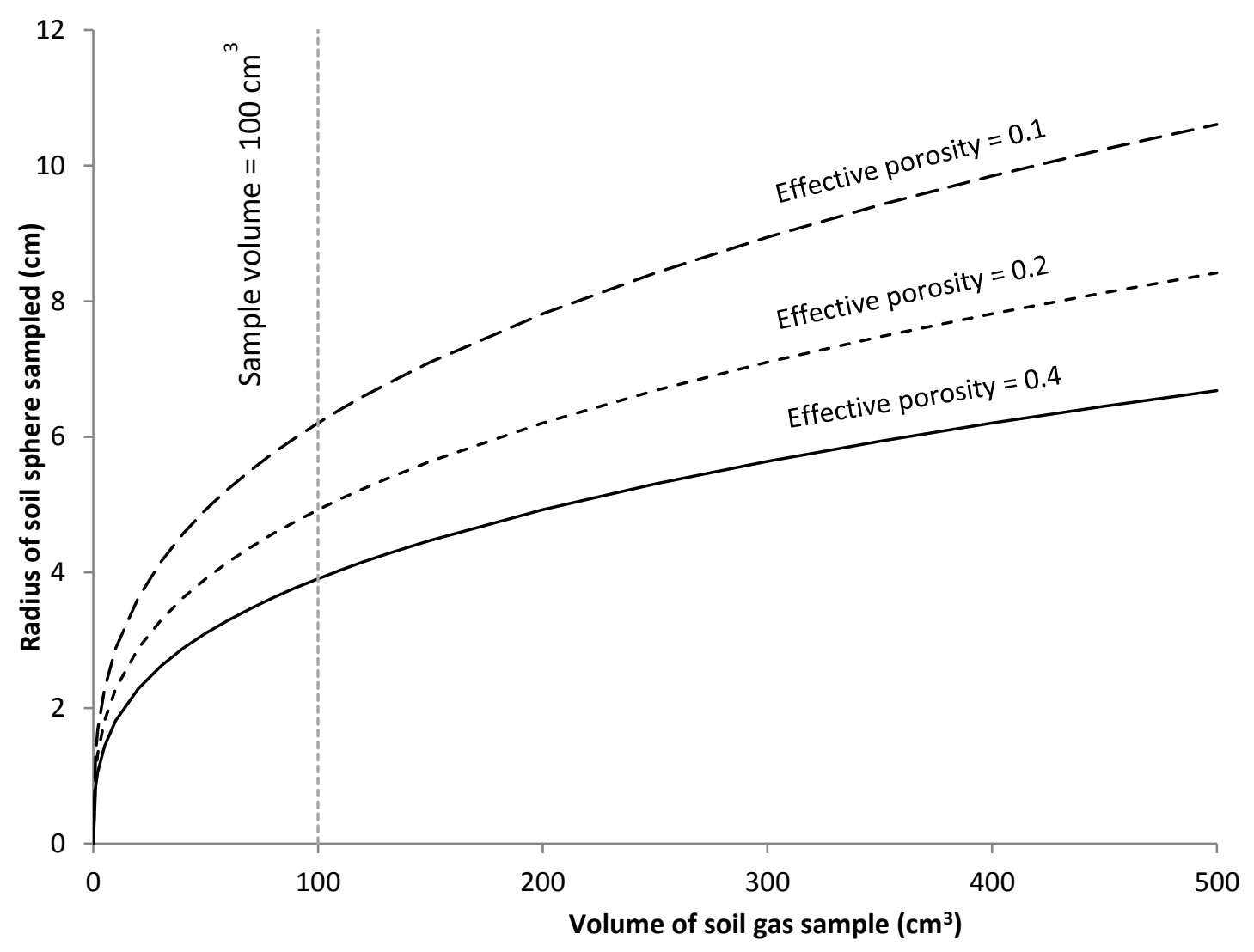

427

428

429

Figure 1. Influence of soil gas sample volume on effective radius of soil sphere sampled.

430

431

432

433 
436

437 Soil gas drawn through

$4381 \mathrm{~mm} \varnothing$ perforations

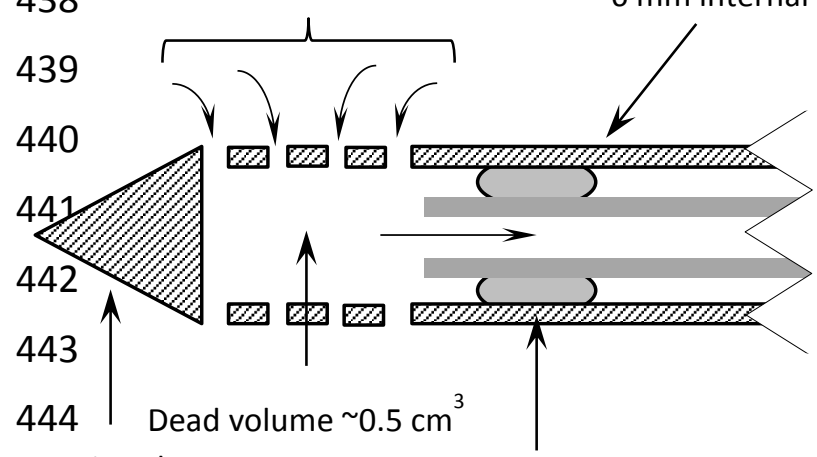

$44^{\text {Pointed }}$

aluminium tip

446

447

448

449

450

451

452

453

454

455

456

457

458

459

460

461

462

463

464

465

466

467

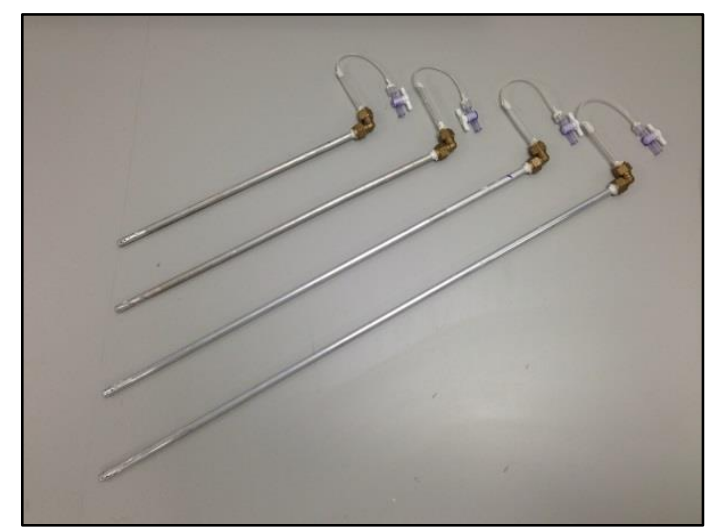
$1 \mathrm{~m}$.
External aluminium tube

(8 $\mathrm{mm}$ external $\varnothing$,

$6 \mathrm{~mm}$ internal $\varnothing)$
Silicone rubber tube

(0.8 mm internal $\varnothing$ )
Brass 'elbow' joint

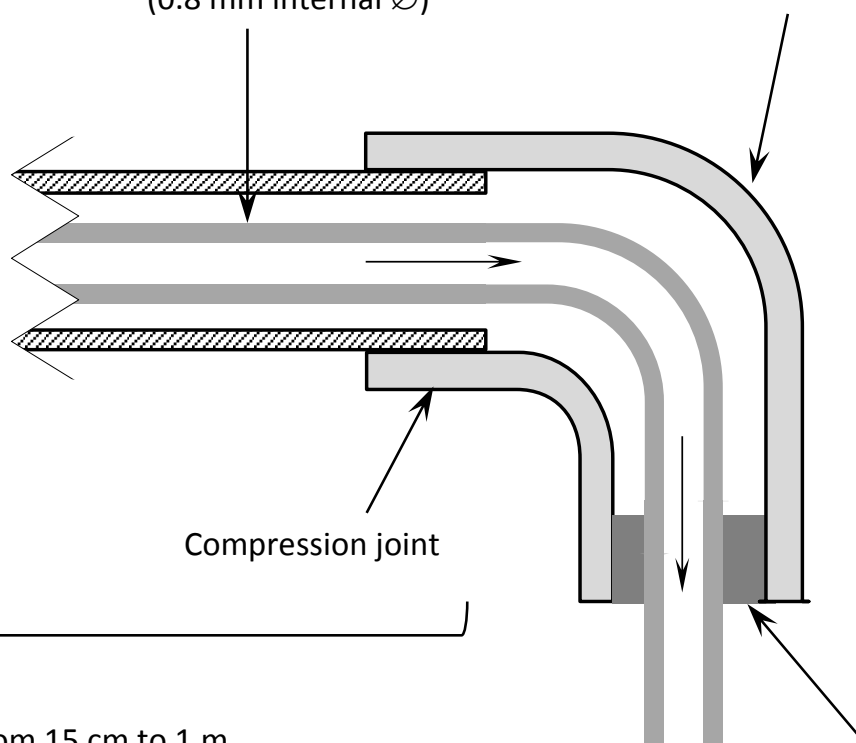

Sampler tube length ranges from $15 \mathrm{~cm}$ to $1 \mathrm{~m}$, according to application

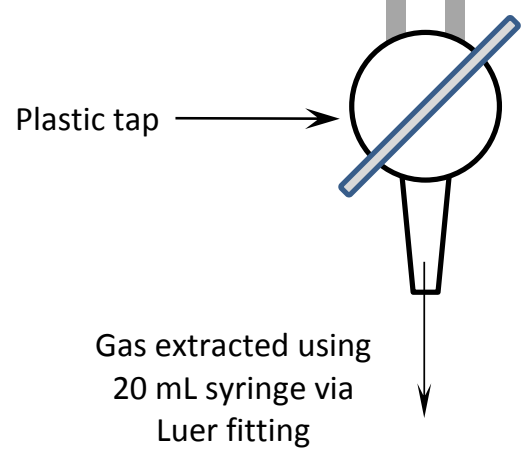

Figure 2. Cross-sectional diagram of soil gas sampling tubes. Sampler head dead volume $\sim 0.5 \mathrm{~cm}^{3}$; sampler tube dead volume $=0.5 \mathrm{~cm}^{3} \mathrm{~m}^{-1}$. Inset shows samplers of different lengths, from $45 \mathrm{~cm}$ to 


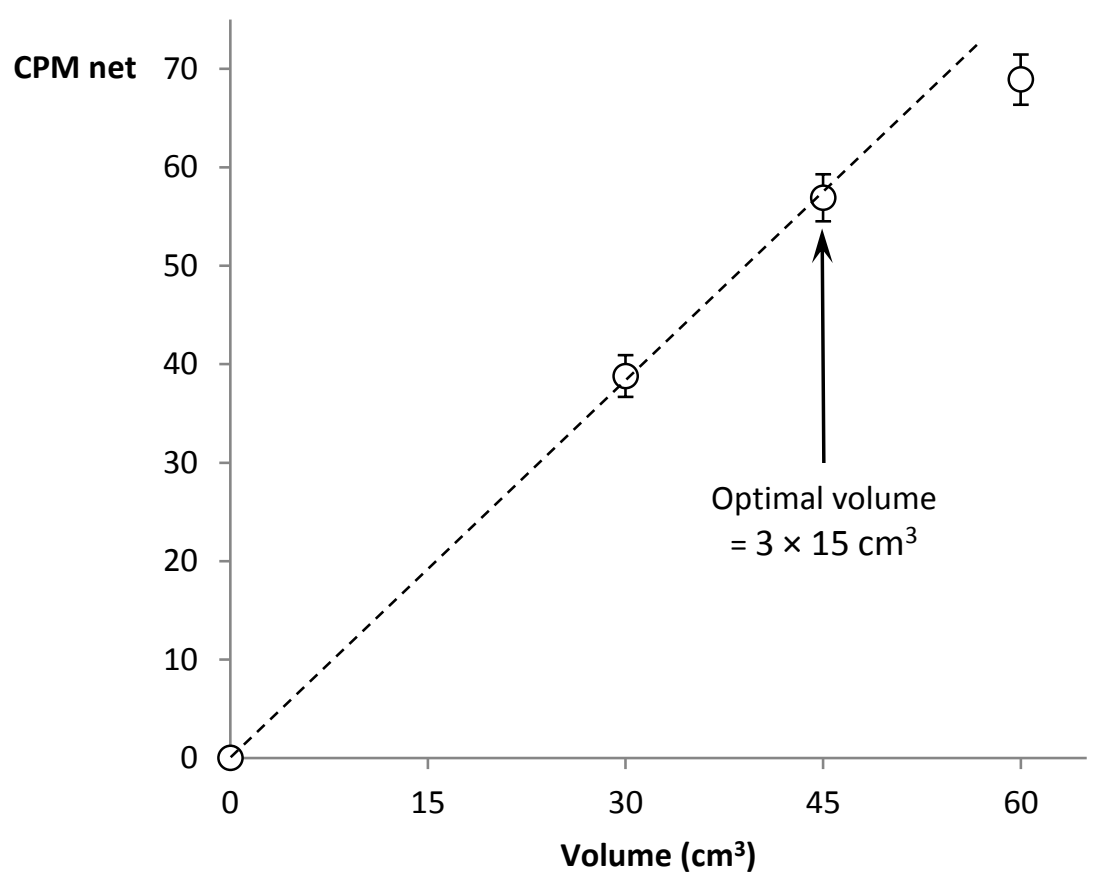

470

471

472

473 Figure 3. Radon-222 activity (CPM net) in ProScint $\mathrm{Rn}^{\mathrm{TM}}$ liquid scintillation vial versus volume of soil

474 gas injected / partitioned in scintillation cocktail. Vertical bars represent 2-sigma counting errors.

475

476

477

478

479

480

481

482 


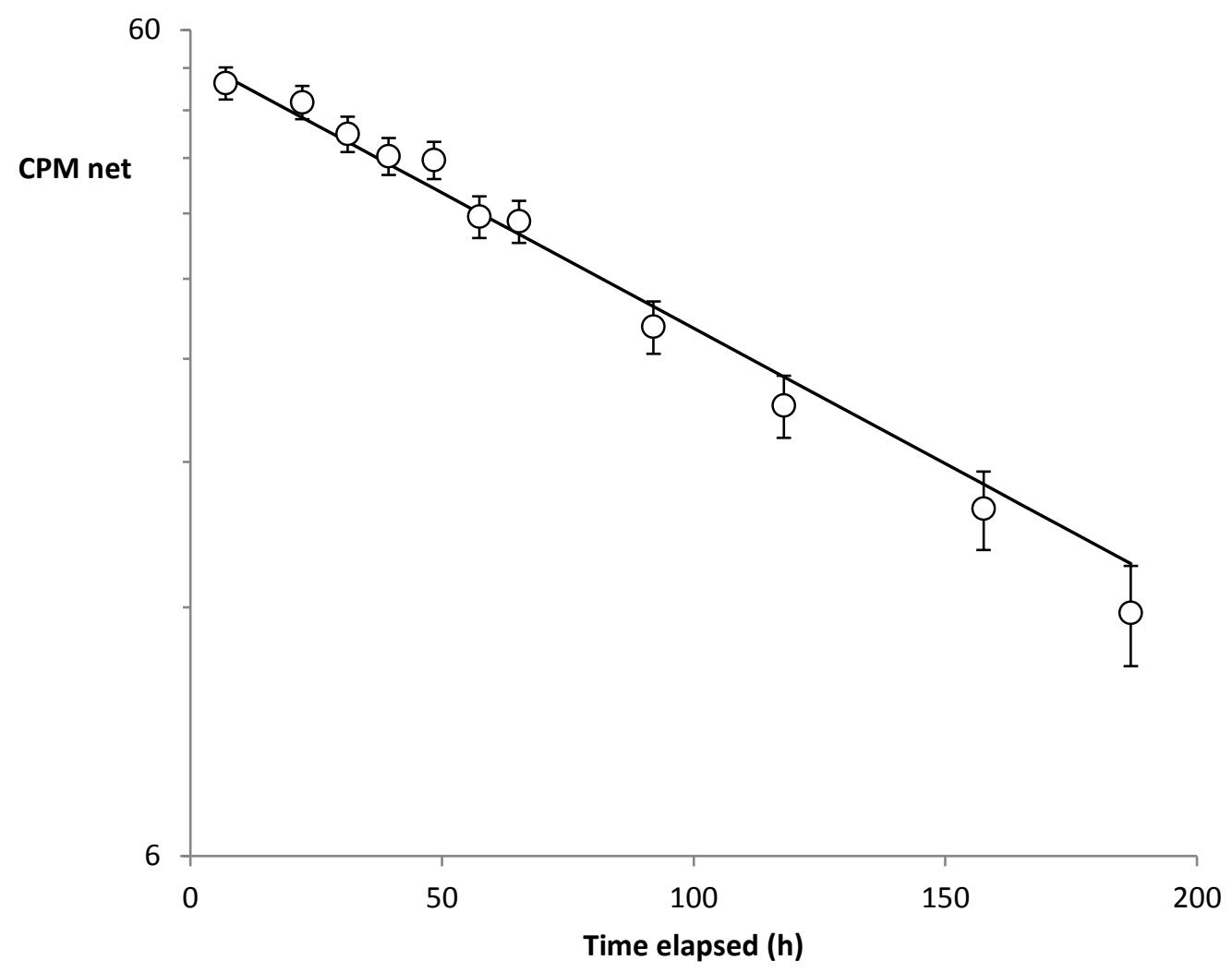

483

484

485

486 Figure 4. Radon-222 activity (CPM net) in a liquid scintillation vial counted repeatedly after sampling

487 from soil gas and partitioning into ProScint $\mathrm{Rn}^{\mathrm{TM}}$ liquid scintillation cocktail. Vertical bars represent

488 2-sigma counting errors. The solid line shows the curve of declining activity expected if ${ }^{222} \mathrm{Rn}$ and its 489 short-lived progeny are the sole contributors to radioactivity within the vial; the measured and 490 calculated activities were statistically indistinguishable $\left(\chi^{2}=1.001, p<0.001\right)$.

491

492

493 


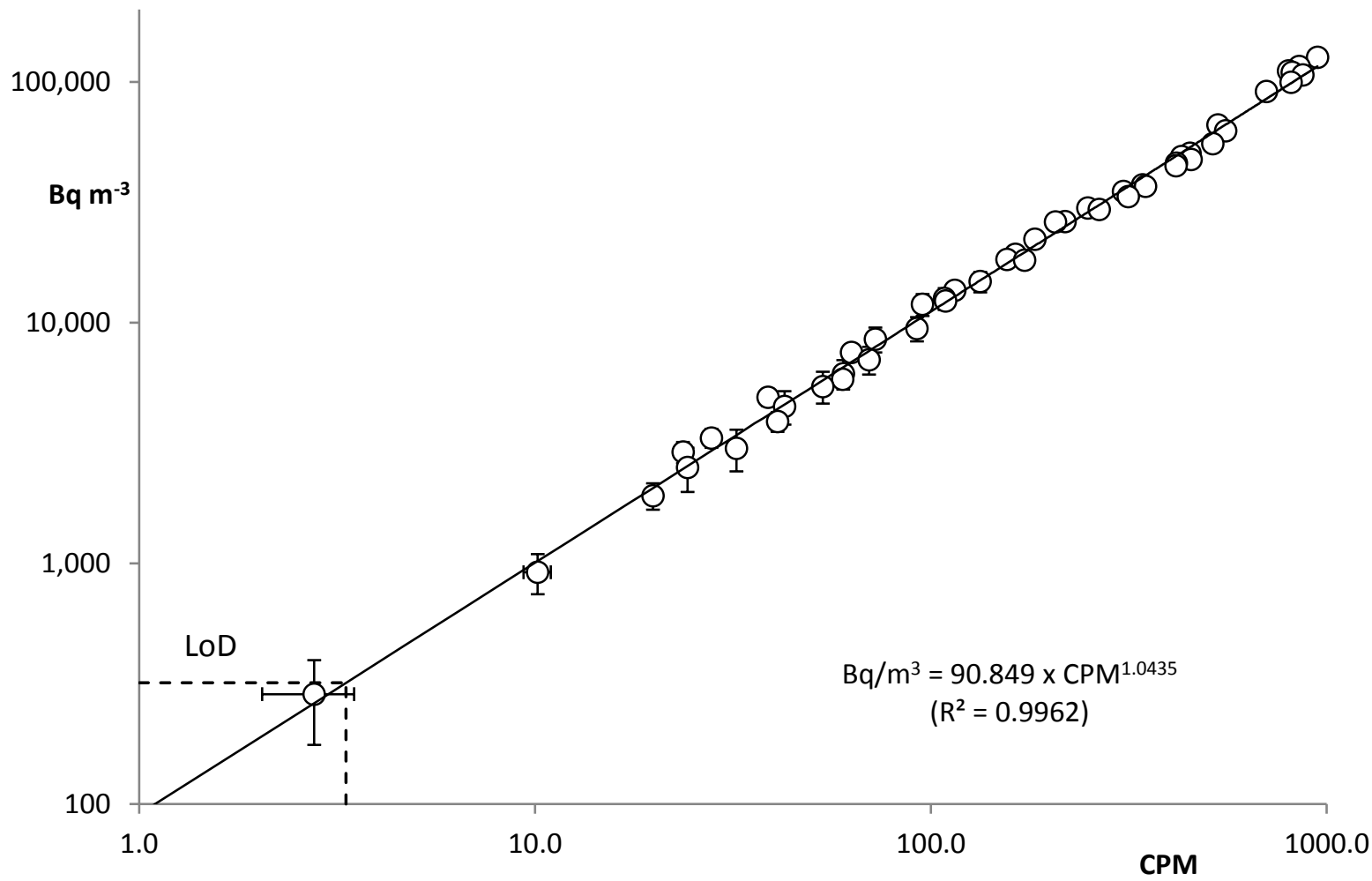

Figure 5. Radon-222 activities in gas samples obtained using two detection methods: liquid scintillation counting (CPM net) and an ionisation chamber (AlphaGUARD ${ }^{\mathrm{TM}}, \mathrm{Bq} \mathrm{\textrm {m } ^ { - 3 }}$ ). The AlphaGUARD' ${ }^{\mathrm{TM}}$ was used in 'flow' mode with a 10 minute count. Measurements were made using gas samples from a closed chamber system with barium-radium sulphate scale as the source of ${ }^{222} \mathrm{Rn} ; 45 \mathrm{~cm}^{3}\left(3 \times 15 \mathrm{~cm}^{3}\right)$ samples for liquid scintillation counting were taken directly from the ionization chamber of the AlphaGUARD ${ }^{\mathrm{TM}}$ instrument. Horizontal and vertical bars are 1-sigma errors; dashed lines show the limit of detection (LoD - 3.33 CPM, equivalent to $320 \mathrm{~Bq} \mathrm{~m}^{-3}$ ) which was calculated according to Currie (1968) based on liquid scintillation counting for 60 minutes in ProScint $\mathrm{Rn}^{\mathrm{TM}}$.

507

508

509

510 


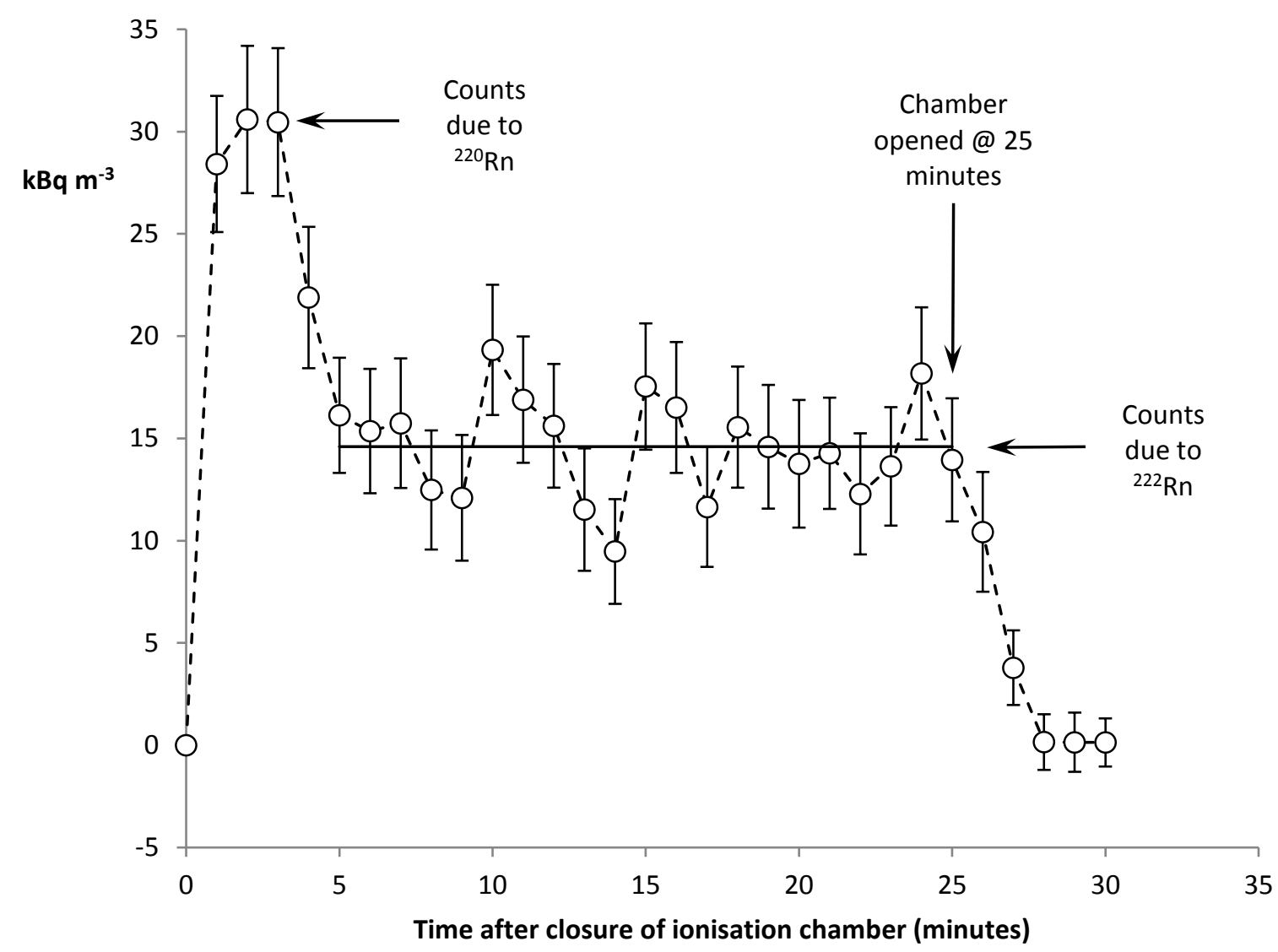

525 Figure 6. Typical activity concentration data from a 30 minute AlphaGUARD' ${ }^{\text {TM }}$ counting cycle in the 526 field. The $X$ axis shows time after a soil gas sample is sealed in the ionisation chamber. Vertical bars 527 represent 1-sigma errors on 1 minute counts. 


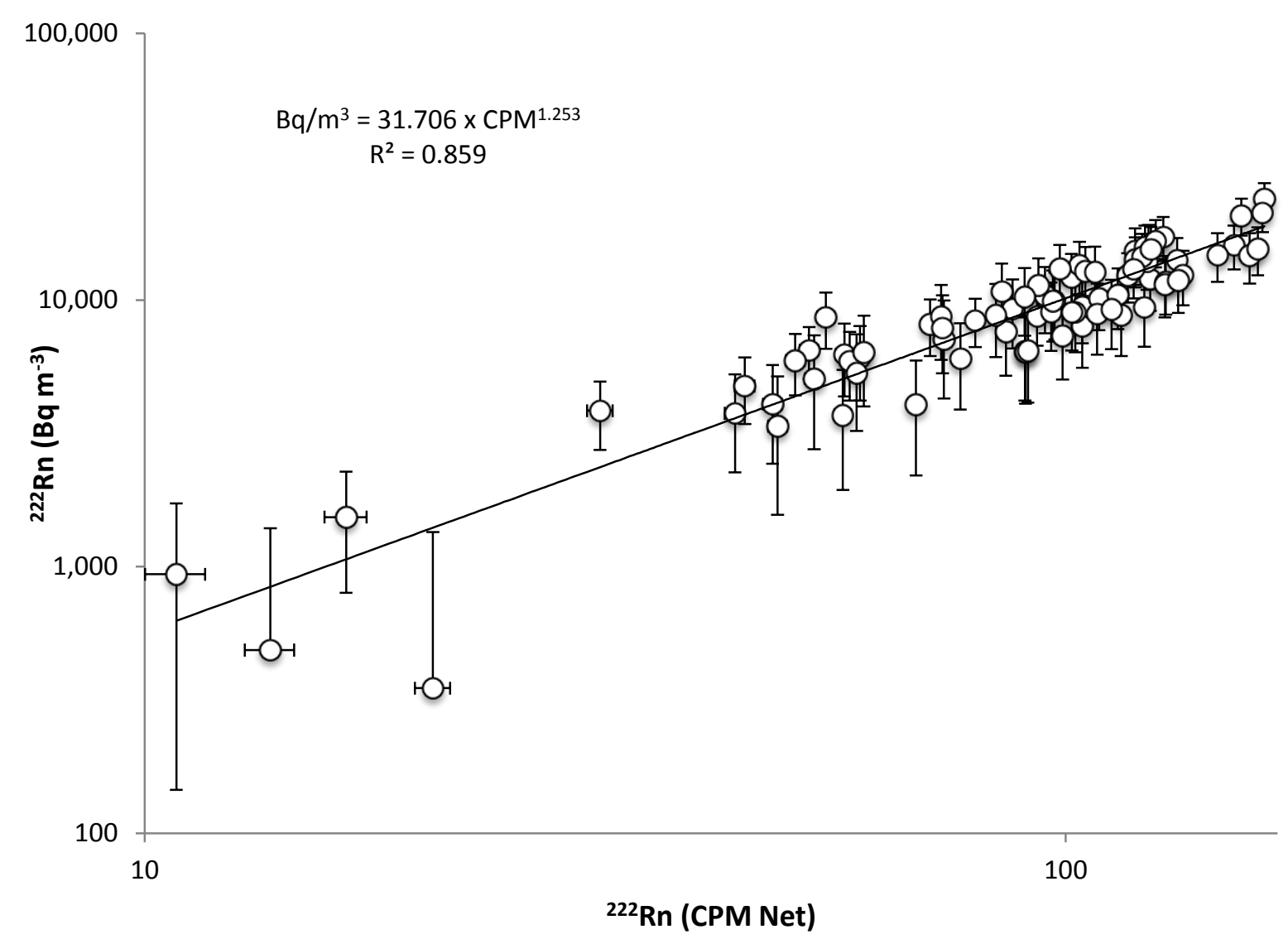

530

531 Figure 7. Radon-222 activity concentrations in field samples of soil gas (60 cm depth) measured on 532 seven different days between September and December 2013 using two detection methods: liquid 533 scintillation counting (CPM net) and an ionisation chamber (AlphaGUARD ${ }^{\mathrm{TM}}, \mathrm{Bq} \mathrm{m}^{-3}$ ). The 534 AlphaGUARD' was used in 'flow' mode with a 1 minute count time following purging of the 535 ionisation chamber with two chamber volumes (total volume sampled $\sim 2$ litres). $45 \mathrm{~cm}^{3}$ (3 315 $536 \mathrm{~cm}^{3}$ ) samples were removed directly from the ionisation chamber for analysis by LSC. Vertical and 537 horizontal bars are 1-sigma errors. 


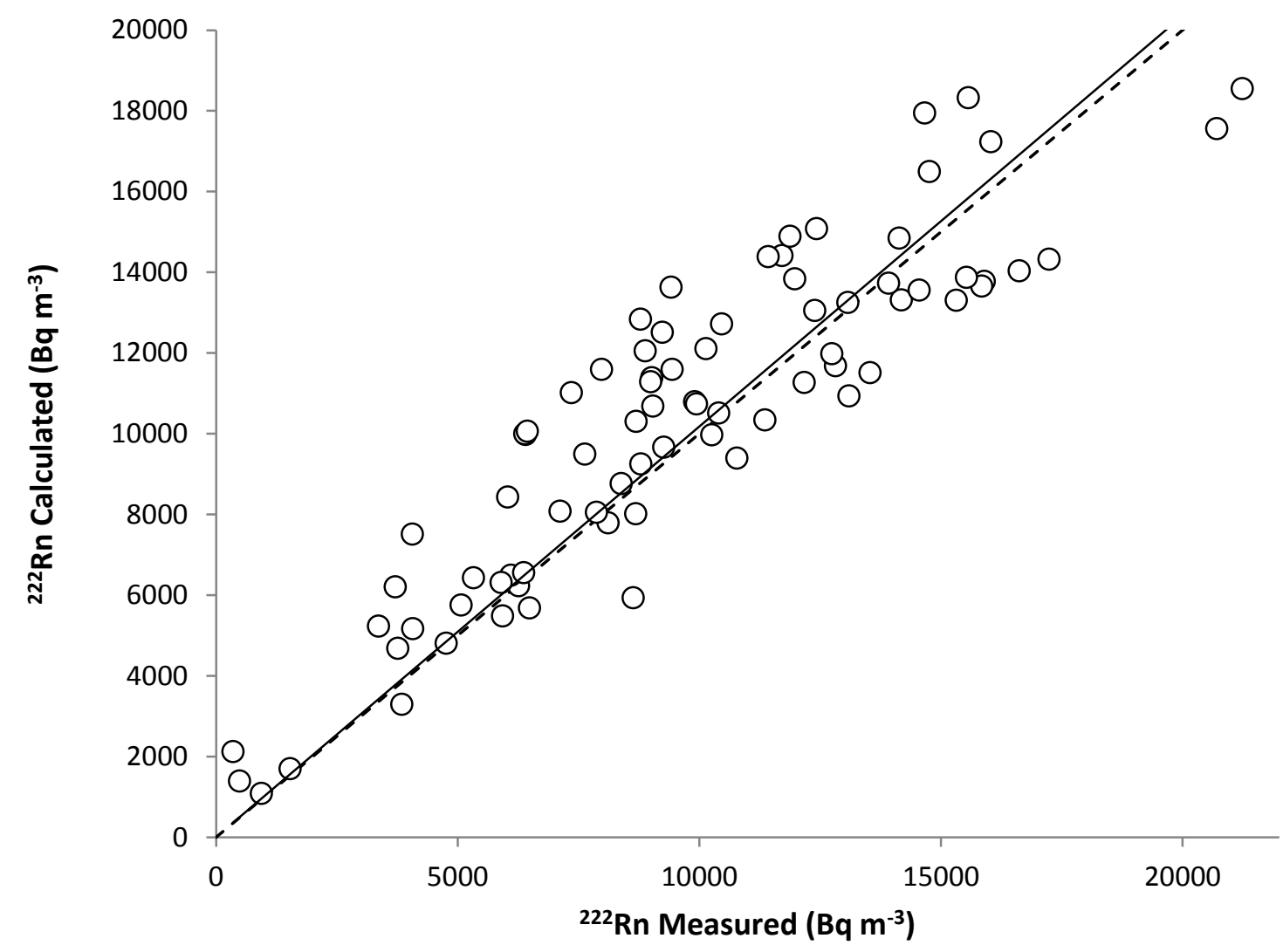

538

539

540 Figure 8. Comparison of ${ }^{222} \mathrm{Rn}$ activity concentrations in field samples of soil gas (60 $\mathrm{cm}$ depth)

541 measured on seven different days between September and December 2013. Measurements were

542 made in the field with AlphaGUARD ${ }^{\mathrm{TM}}$ ( $\mathrm{X}$ axis) and in the laboratory by liquid scintillation counting,

543 using the calibration curve in Figure 5 to convert CPM (net) to $\mathrm{Bq} \mathrm{m}^{-3}$. The dashed line is the line of 544 unity while the solid line is a linear regression $\left(R^{2}=0.742\right)$. The measured and calculated values 545 were statistically indistinguishable $\left(\chi^{2}=0, p=0\right)$. 


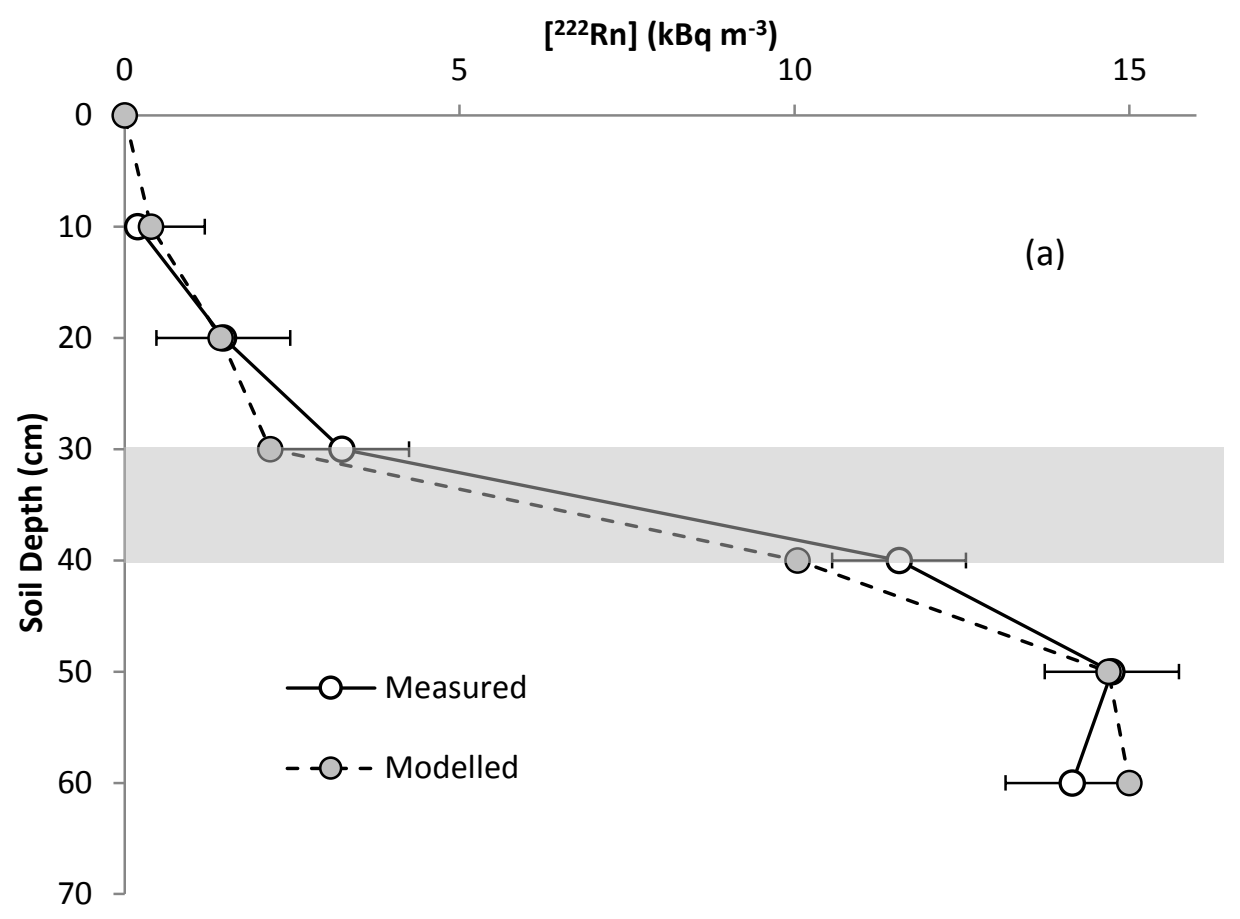

546

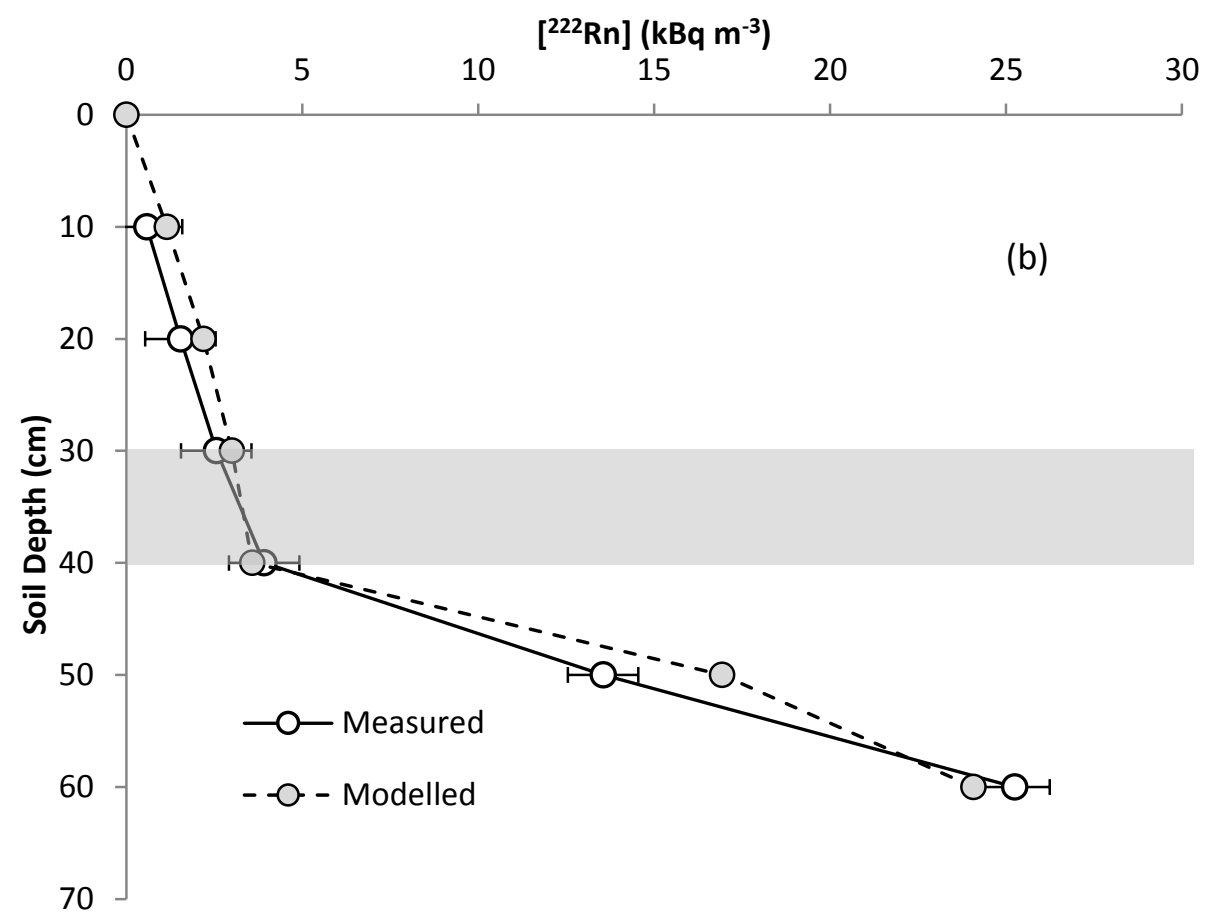

549 Figure 9. Two depth profiles of ${ }^{222} \mathrm{Rn}$ measured within a $15 \mathrm{~m} \times 15 \mathrm{~m}$ plot in Sutton Bonington soil.

550 Also shown are modelled curves using numerical solutions of the 1-D diffusion equation (see text for 551 model parameters). The horizontal grey bar indicates the depth at which the soil texture changes 552 from sandy loam to sandy clay, with a consequent change in effective diffusion coefficient for ${ }^{222} \mathrm{Rn}$ 553 and other gases. Error bars represent 2-sigma counting errors on measured ${ }^{222} \mathrm{Rn}$ activity 554 concentrations. 


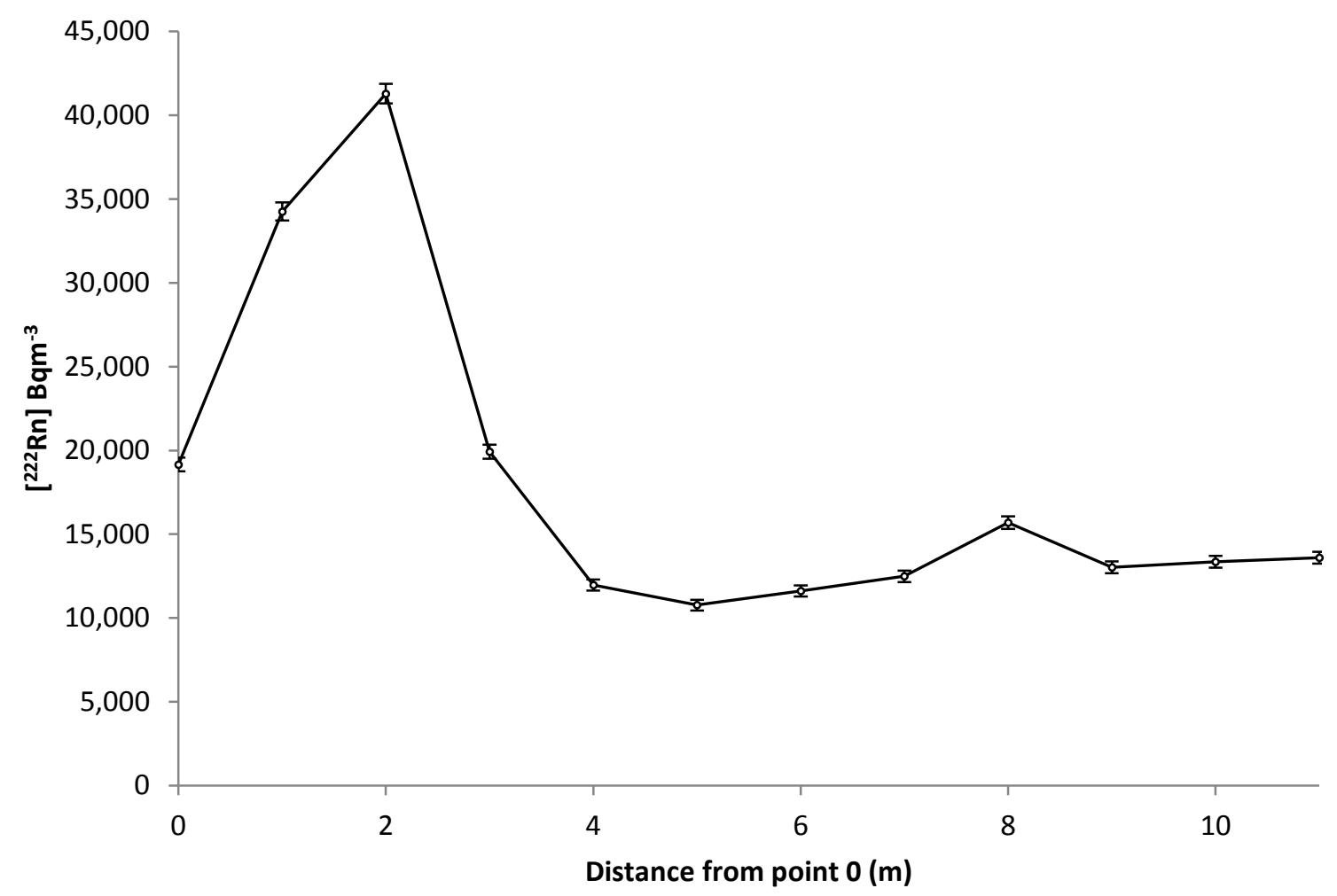

556

557

558 Figure 10: Radon-222 activity concentrations measured in soil gas sampled at $15 \mathrm{~cm}$ depth on 559 Cromford Meadow (UK, $53.110^{\circ} \mathrm{N}, 1.549^{\circ} \mathrm{W}$ ) along a transect perpendicular to the boundary 560 between the uraniferous Bowland Shale and Lower Carboniferous Limestone. Measurements were 561 made using liquid scintillation counting; 2-sigma counting errors are plotted as vertical bars. 